\title{
Cellulose
}

\section{Ethyl Cellulose, Cellulose Acetate and Carboxymethyl Cellulose Microstructures Prepared using Electrohydrodynamics and Green Solvents \\ --Manuscript Draft--}

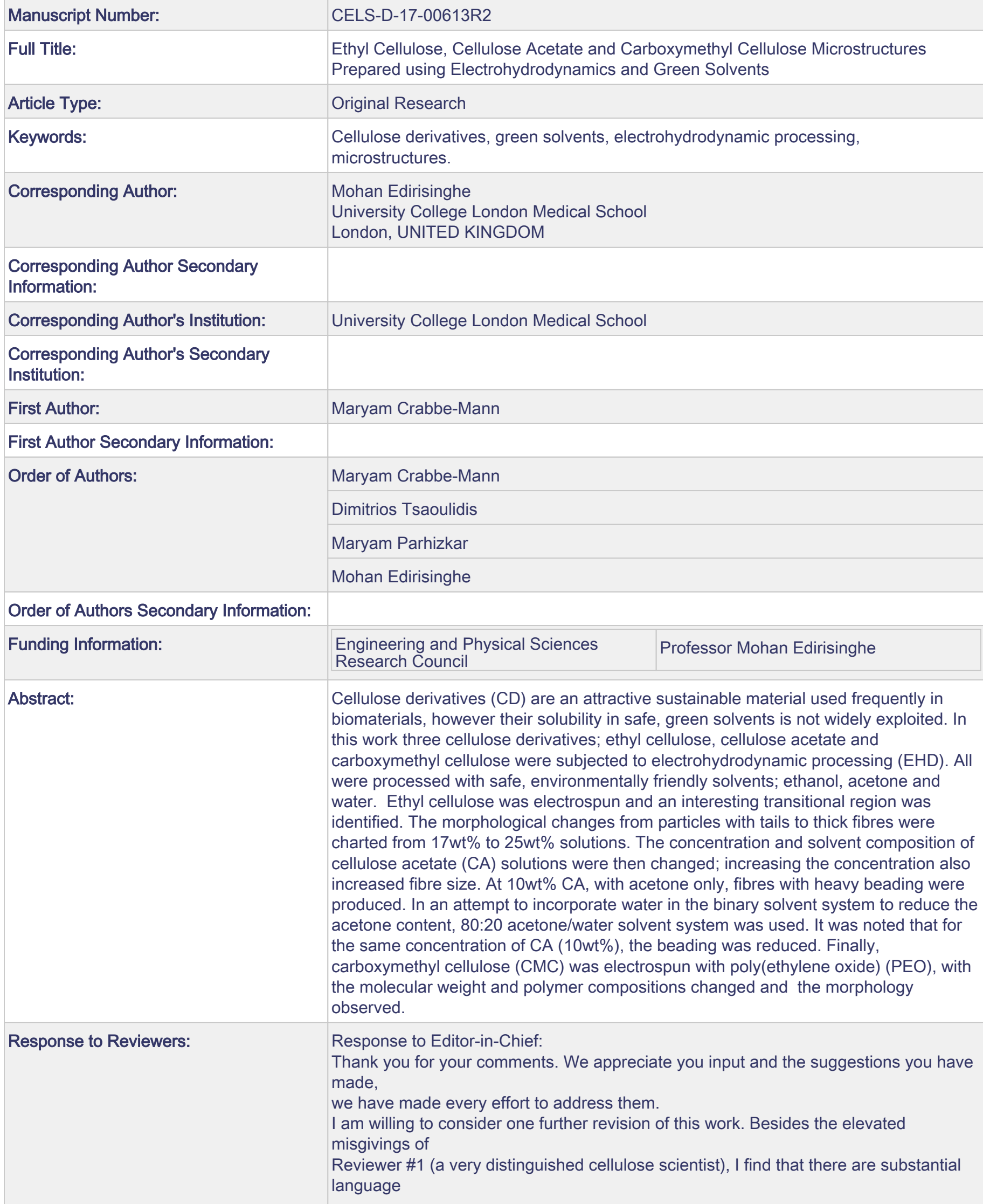


problems that interfere with the understanding of the work. Also, the closing sentence of the abstract suggests that the diameter difference is not significant. That indicates poor analysis;

what are we to imagine regarding less obvious places?

I do not find that it is an especially worthwhile goal to replace cellulose in biomedical materials

when cellulose is functional and can be chemically modified for specific purposes.

Rather, the

different morphologies that allow new applications would be meritorious.

We have revised the document to address the language matter. We do not intend to replace

cellulose, our argument was cellulose derivatives are easier to electrospin compared to cellulose. However, we have removed these statements as we do not want to prevent any confusion. Our aim is to highlight processing cellulose derivatives with safe solvents and

produce a range of structures on order to encourage the use of all cellulose and these solvents.

Response to Reviewer 1:

Thank you for your review of our manuscript. We appreciate the detail you have presented and

have made every effort to take these on board and address each point.

2. The frequent mentions about the difficulty of solubilizing cellulose and the connexion to the

present study is confusing. The fact that this investigation dealt with three cellulose derivatives

DOES NOT solve the problem of cellulose processing, simply because the three substrates are

NOT cellulose itself. In other words, whereas the study is interesting, it does not deal with

cellulose and hence it should be treated within its context without giving the idea that somehow

it provides a means to solve the cellelose processing problems, because it does not.

This study does not propose a solution to the solubility of cellulose. Instead, we wish to highlight the EHD processing of cellulose derivatives using safe solvents such as water, as this

is not widely exploited. Electrospinning these derivatives with the solvents stated is very

difficult. The volatile nature of ethanol and acetone make continuous production difficult.

Water also poses problems with electrospinning, its high surface tension clash with the entire

process, however, their non-toxic nature and availability outweigh these issues, pursuing this

avenue of "green electrospinning" is important in terms of biomaterials and

sustainability as a

whole. We hope we have now made this clear in the revised manuscript.

4. The discussion of the results often lacks of depth and is therefore sometimes unconvincing,

particularly in the case of CMC.

The discussion in this work describe the morphologies produced via electrospinning the

cellulose derivatives. Through changing various parameters different structures were produced

and their fabrication was explained through established EHD principles. We have described in

detail the procedures that have given rise to each of the different morphologies as we have

changed parameters. We hope we have modified the text sufficiently while not losing form of our

study as entitled it is a study of microstructures and we have made every effort to describe how

they were prepared. 
Re.: Submission of revised paper "Ethyl Cellulose, Cellulose Acetate and Carboxymethyl Cellulose Microstructures Prepared using Electrohydrodynamics and Green Solvents". Manuscript number CELS-D-17-00613.

Friday $19^{\text {th }}$ January 2017

Dear Editor,

Thank you for your email dated 21/10/2017 enclosing the reviewers' comments. We would like to thank the reviewer for their comments, they were critical but constructive, we appreciate the time they have taken to do this. We have carefully read the comments and have applied the appropriate revisions to the manuscripts. We have addressed each point individually below. The changes in the manuscript have been highlighted in red.

We hope the revised manuscript now meets the standard required for Cellulose and we look forward to hearing from you.

Yours faithfully,

Prof. Mohan Edirisinghe

(Corresponding author) 


\section{Response to Editor-in-Chief:}

Thank you for your comments. We appreciate you input and the suggestions you have made, we have made every effort to address them.

I am willing to consider one further revision of this work. Besides the elevated misgivings of Reviewer \#1 (a very distinguished cellulose scientist), I find that there are substantial language problems that interfere with the understanding of the work. Also, the closing sentence of the abstract suggests that the diameter difference is not significant. That indicates poor analysis; what are we to imagine regarding less obvious places?

I do not find that it is an especially worthwhile goal to replace cellulose in biomedical materials when cellulose is functional and can be chemically modified for specific purposes. Rather, the different morphologies that allow new applications would be meritorious.

We have revised the document to address the language matter. We do not intend to replace cellulose, our argument was cellulose derivatives are easier to electrospin compared to cellulose. However, we have removed these statements as we do not want to prevent any confusion. Our aim is to highlight processing cellulose derivatives with safe solvents and produce a range of structures on order to encourage the use of all cellulose and these solvents. 
Response to Reviewer 1:

Thank you for your review of our manuscript. We appreciate the detail you have presented and have made every effort to take these on board and address each point.

2. The frequent mentions about the difficulty of solubilizing cellulose and the connexion to the present study is confusing. The fact that this investigation dealt with three cellulose derivatives DOES NOT solve the problem of cellulose processing, simply because the three substrates are NOT cellulose itself. In other words, whereas the study is interesting, it does not deal with cellulose and hence it should be treated within its context without giving the idea that somehow it provides a means to solve the cellelose processing problems, because it does not.

This study does not propose a solution to the solubility of cellulose. Instead, we wish to highlight the EHD processing of cellulose derivatives using safe solvents such as water, as this is not widely exploited. Electrospinning these derivatives with the solvents stated is very difficult. The volatile nature of ethanol and acetone make continuous production difficult. Water also poses problems with electrospinning, its high surface tension clash with the entire process, however, their non-toxic nature and availability outweigh these issues, pursuing this avenue of "green electrospinning" is important in terms of biomaterials and sustainability as a whole. We hope we have now made this clear in the revised manuscript.

4. The discussion of the results often lacks of depth and is therefore sometimes unconvincing, particularly in the case of CMC.

The discussion in this work describe the morphologies produced via electrospinning the cellulose derivatives. Through changing various parameters different structures were produced and their fabrication was explained through established EHD principles. We have described in detail the procedures that have given rise to each of the different morphologies as we have 
changed parameters. We hope we have modified the text sufficiently while not losing form of our study as entitled it is a study of microstructures and we have made every effort to describe how they were prepared. 
1 Ethyl Cellulose, Cellulose Acetate and Carboxymethyl Cellulose

2 Microstructures Prepared using Electrohydrodynamics and Green Solvents

$4{ }^{1}$ Department of Mechanical Engineering, University College London, London, WC1E 7JE, UK

$5 \quad{ }^{2}$ Department of Chemical Engineering, University College London, London, WC1E 7JE, UK

$6 \quad *$ Corresponding author email: m.edirisinghe@ucl.ac.uk

\section{Abstract}

8 Cellulose derivatives (CD) are an attractive sustainable material used frequently in

9 biomaterials, however their solubility in safe, green solvents is not widely exploited. In this

10 work three cellulose derivatives; ethyl cellulose, cellulose acetate and carboxymethyl cellulose were subjected to electrohydrodynamic processing (EHD). All were processed with safe, environmentally friendly solvents; ethanol, acetone and water. Ethyl cellulose was electrospun and an interesting transitional region was identified. The morphological changes from particles with tails to thick fibres were charted from $17 \mathrm{wt} \%$ to $25 \mathrm{wt} \%$ solutions. The concentration and solvent composition of cellulose acetate (CA) solutions were then changed; increasing the concentration also increased fibre size. At $10 \mathrm{wt} \% \mathrm{CA}$, with acetone only, fibres with heavy beading were produced. In an attempt to incorporate water in the binary solvent system to reduce the acetone content, 80:20 acetone/water solvent system was used. It was noted that for the same concentration of CA $(10 \mathrm{wt} \%)$, the beading was reduced. Finally, carboxymethyl cellulose (CMC) was electrospun with poly(ethylene oxide) (PEO), with the molecular weight and polymer compositions changed and the morphology observed.

Keywords: Cellulose derivatives, Green Solvents, electrohydrodynamic processing, microstructures. 


\section{Introduction}

27 Electrohydrodynamic processing of cellulose derivatives (Son, Youk et al. 2003, Frenot, Henriksson et al. 2007, Frey 2008) is becoming increasingly popular due to it sustainable origins and its solubility in organic solvents. Cellulose derivatives (CD's) are commonly used as biomaterials in drug encapsulation (Eltayeb, Bakhshi et al. 2013), wound patches (Son, Youk et al. 2006) and even as a drug release controlling matrix in oral doses (Shokri and Adibki 2013). However, much of the processing involved uses solvents which are considered toxic and harmful to the environment. Post processing such as freeze drying or vacuum drying are options ensure any solvent residues are removed, although this will increase production time and costs too. Whereas, this step can be avoided if safe solvents can utilised instead. Although CD's can be processed using safer solvents, it is overlooked due to the ease of processing with solvents such as chloroform, N,N-dimethylacetamide, N,N-dimethylformamide and formic acid (Tungprapa, Puangparn et al. 2007) used with cellulose acetate or 2,2,2-trifluoroethanol (Jeun, Lim et al. 2007) and dichloromethane (Duarte, Gordillo et al. 2006) used with ethyl cellulose. Electrospinning with organic solvents can be difficult i.e. the volatility of acetone can cause blockages as the solution dries up and the high surface tension of water can also cause difficulties.

The electrohydrodynamic processing of cellulose derivatives goes back to Formhals (Formhal 1934), where two of his original patents used cellulose acetate and propionyl cellulose to form fibres. Electrohydrodynamic (EHD) processing is an easy and cost effective process (Reneker,

46 Yarin et al. 2000) that uses an electric field to distort a polymeric droplet by inducing repulsion

47 between the polymeric chains, thus overcoming the surface tension and allowing a jet to be formed. Depending on the solution properties, primarily concentration, either electrospinning or electrospraying will occur, thereby producing fibres or particles, respectively (Agarwal,

50 Wendorff et al. 2008). The EHD process is able to produce a range of structures; particles, 
51 beaded fibres, smooth fibres and ribbons, making it attractive manufacturing procedure in

52

53

54 many industries (Agarwal, Wendorff et al. 2008). Solvent evaporation occurs as the jet travels towards the collector (Shenoy, Bates et al. 2005), in the case solvent residues are present water and ethanol would be preferable opposed to previous mentioned solvents.

In an effort to push CD's further as a biomaterial, the solvent problem must be tackled and reported. Ethyl cellulose (EC) is non-ionic and hydrophobic but soluble in polar solvents such as ethanol (Park, Kim et al. 2015). Previously implanted by Miyamoto et al. (Miyamoto, Takahashi et al. 1989) showed EC was not absorbed by living tissue after implantation in dogs. Electrospun CA is used widely in medical applications, such as cell culture and regenerative medicine, and drug delivery (Cui, Zhou et al. 2016). CA has excellent water retention properties, which is a desirable trait in wound dressing, where absorbing wound exudate is an important function (Liu, Lin et al. 2012).

Carboxymethyl cellulose (CMC) is a water soluble derivative of cellulose, and a known mucoadhesive (Brako, Raimi-Abraham et al. 2015).

There is a trend to embrace in "green" electrospinning which involves the use of solvents which are typically non-toxic and biocompatible like ethanol or phosphate buffered saline (CastillaCasadiego, Maldonado et al. 2016). The choice of solvent must also be balanced against the desired morphology, as different solvent systems have been used with varied results. As Tungprapa et al. (Tungprapa, Puangparn et al. 2007) demonstrated with electrospun CA; in acetone/dimethylacetamide 2:1, beaded fibres were produced whereas CA in dichloromethane/methanol 4:1 formed smooth fibres. The use of volatile, organic solvents such as acetone can give rise to porous or beaded fibre morphologies as it has a high evaporation rate, conversely adding water can "smoothen out" fibres, as water has a higher viscosity than acetone (Luo, Stride et al. 2012). 
EC was processed using a binary solvent made from water and ethanol (EtOH) (Luo, Nangrejo et al. 2010), despite its hydrophobic nature. Decreasing the EtOH content, reduces the potential amount of EtOH residue in the final polymeric fibres/particles, which is a mild irritant (Loffler, Kampf et al. 2007). It is ideal to keep the EtOH content to a minimum, however, this has to be balanced against solubilizing the polymer. Increasing the proportion of water above $20 \%(\mathrm{v} / \mathrm{v})$ will form solid suspensions whilst further increase will show no solubility.

Previous investigations into the effect of solvent selection on the morphology of electrospun CA fibres (Liu and Hsieh 2002, Tungprapa, Puangparn et al. 2007), however, were carried out without a specific application in mind and therefore toxicology was not taken into consideration.

Carboxymethyl cellulose has been predominantly used with water, with the exception of Kessick and Tepper's (Kessick and Tepper 2003) work, where CMC was dissolved in a mixture of methanol and water.

This work will demonstrate that ethyl cellulose, cellulose acetate, and carboxymethyl cellulose can produce a wide range of microstructures with the one step EHD process, using environmentally friendly solvent systems. This study focuses on optimising the processing conditions of cellulose derivatives with the aim to produce non-woven fibrous wound healing patches. The parameters studied were solution properties; concentration, solvent composition, polymer molecular weight and polymer composition. Processing parameters were also altered, specifically; applied voltage, flow rate, needle to collector distance and finally the effect of attaching a guard plate to the EHD needle on the microstructures. 


\section{Experimental Details}

\subsection{Materials}

102

In the following table the polymers, additives, solvents and resulting solutions used in this work are described.

\begin{tabular}{|c|c|c|c|c|c|}
\hline Material & Abbreviation & $\begin{array}{l}\text { Molecular } \\
\text { weight/g } \\
\text { mol }^{-1}\end{array}$ & $\begin{array}{ll}\text { Degree } & \text { of } \\
\text { substitution }\end{array}$ & $\begin{array}{l}\text { Concentration/ } \\
\text { wt\% }\end{array}$ & Solvent \\
\hline Ethyl cellulose & $\mathrm{EC}$ & 22,800 & $48 \%$ ethoxyl & $17-25$ & $\begin{array}{l}\text { Ethanol/ } \\
\text { water at } \\
80: 20(\mathrm{v} / \mathrm{v})\end{array}$ \\
\hline \multirow[t]{2}{*}{$\begin{array}{l}\text { Cellulose } \\
\text { acetate }\end{array}$} & \multirow[t]{2}{*}{$\mathrm{CA}$} & \multirow[t]{2}{*}{$30,000 \mathrm{M}_{\mathrm{n}}$} & \multirow[t]{2}{*}{$39.8 \%$ acetyl } & $\begin{array}{l}10,12.5,15 \text { and } \\
17.5\end{array}$ & Acetone \\
\hline & & & & 10 & $\begin{array}{l}\text { Acetone/ } \\
\text { Water at } \\
80: 20 \quad- \\
100: 0(\mathrm{v} / \mathrm{v})\end{array}$ \\
\hline $\begin{array}{l}\text { Sodium } \\
\text { Carboxymethyl } \\
\text { cellulose }\end{array}$ & CMC 25 & 250,000 & $\begin{array}{l}0.9 \\
\text { carboxymethyl } \\
\text { groups per } \\
\text { anhydroglucose } \\
\text { group }\end{array}$ & 4 & Water \\
\hline $\begin{array}{l}\text { Sodium } \\
\text { Carboxymethyl } \\
\text { cellulose }\end{array}$ & CMC 70 & 700,000 & $\begin{array}{l}0.9 \\
\text { carboxymethyl } \\
\text { groups per } \\
\text { anhydroglucose } \\
\text { group }\end{array}$ & 1 & Water \\
\hline $\begin{array}{l}\text { Poly(ethylene } \\
\text { oxide) }\end{array}$ & PEO & $200,000 \mathrm{M}_{\mathrm{v}}$ & & 15 & Water \\
\hline
\end{tabular}

Table 1: Materials used in this work. Molecular weight is $M_{w}$ unless indicated. Where $M_{n}$ is molecular number and $\mathrm{M}_{\mathrm{v}}$ is molecular volume.

\subsection{Solution Preparation}

Ethyl cellulose 5-30wt\% and 17-25wt\% were dissolved in ethanol and distilled water (80:20

vol. ratio), respectively. Cellulose acetate $10,12.5,15$, and $17.5 \mathrm{wt} \%$ were dissolved in acetone only. Cellulose acetate 10wt\% were dissolved in 100:0, 95:5, 90:10, 85:15, 80:20 acetone: water (vol. ratio). Carboxymethyl cellulose/PEO solutions were made at 25:75, 14:86 and 10:90 wt. ratio with $\mathrm{CMC} \mathrm{M}_{\mathrm{w}}$ equal to 250,000 and 14:86 wt. ratio with $\mathrm{CMC}_{\mathrm{w}}$ equal to 
700,000 . The polymer solutions were mixed at ambient temperature and humidity $\left(21^{\circ} \mathrm{C}\right.$ and $40-50 \%$, respectively) for 24-72 hours, depending on the concentration, , until a homogenous solution formed

\subsection{Solution Characterisation}

118 Viscosity, surface tension, electrical conductivity, and density were characterised for each of the solutions used. Viscosity measurements were conducted using a U-tube viscometer (size G and H, VWR, UK). Surface tension was measured with a tensiometer (Kruss K100, Kruss

GmbH, Hamburg, Germany) using the Wilhelmy's method. The electrical conductivity was measured using a conductivity meter (Jenway 3450, Bibby Scientific Limited, Staffordshire, UK). The density was measured using a standard $5 \mathrm{ml}$ density bottle. All measurements were taken at ambient temperature and humidity $\left(21^{\circ} \mathrm{C}\right.$ and $40-50 \%$, respectively). Values are given in Tables 4-6. Each characterisation was tested 10 times and standard deviation was calculated. The standard deviation for surface tension was $0.1 \mathrm{mN} \mathrm{m}^{-1}, 2.1 \mathrm{mPa}$ s for viscosity and $1.6 \mu \mathrm{S}$ $\mathrm{m}^{-1}$ for electrical conductivity measurements. All equipment used were calibrated with ethanol prior to use.

\begin{tabular}{|c|c|c|c|c|}
\hline $\begin{array}{l}\text { Solution } \\
\text { /wt\% }\end{array}$ & $\begin{array}{l}\text { Density } \\
/ \mathrm{kg} \mathrm{m}^{-3}\end{array}$ & $\begin{array}{l}\text { Viscosity } \\
\text { /mPa s }\end{array}$ & $\begin{array}{l}\text { Surface } \\
\text { Tension } \\
/ \mathbf{m N ~ m}^{-1}\end{array}$ & $\begin{array}{l}\text { Electrical } \\
\text { Conductivity } \\
/ \mu \mathrm{S} \mathrm{m}^{-1}\end{array}$ \\
\hline 5 & 3980 & 30.5 & 18.7 & 55.4 \\
\hline 10 & 4290 & 151.0 & 23.8 & 61.4 \\
\hline 15 & 4450 & 539.0 & 24.0 & 64.4 \\
\hline 20 & 4520 & 800.5 & 26.7 & 62.5 \\
\hline 25 & 4640 & 1652.5 & 27.4 & 57.8 \\
\hline 30 & 4700 & 3008.2 & 35.2 & 51.4 \\
\hline
\end{tabular}

129 Table 2: Characteristics of ethyl cellulose 5-30wt\% solutions used. 


\begin{tabular}{|l|l|l|l|l|}
\hline $\begin{array}{l}\text { Solution } \\
/ \mathbf{w t} \%\end{array}$ & $\begin{array}{l}\text { Density } \\
/ \mathbf{k g ~ m}^{-\mathbf{3}}\end{array}$ & Viscosity & $\begin{array}{l}\text { Surface } \\
\text { Tension } \\
/ \mathbf{m N ~ m}^{-\mathbf{1}}\end{array}$ & $\begin{array}{l}\text { Electrical } \\
\text { Conductivity } \\
/ \mathbf{~ S ~ m ~}^{-\mathbf{1}}\end{array}$ \\
\hline 17 & 4450 & 613.0 & 24.7 & 64.4 \\
\hline 18 & 4460 & 691.3 & 24.8 & 64.0 \\
\hline 19 & 4505 & 750.5 & 25.2 & 63.1 \\
\hline 20 & 4520 & 800.5 & 26.6 & 62.5 \\
\hline 21 & 4550 & 936.7 & 26.6 & 62.0 \\
\hline 22 & 4620 & 1110.6 & 26.8 & 61.4 \\
\hline 23 & 4640 & 1179.6 & 26.9 & 61.0 \\
\hline 24 & 4640 & 1277.9 & 26.9 & 59.6 \\
\hline 25 & 4640 & 1652.5 & 27.7 & 57.8 \\
\hline
\end{tabular}

134 Table 3: Characteristics of ethyl cellulose 17-25wt\% solutions used.

\begin{tabular}{|c|c|c|c|c|c|}
\hline $\begin{array}{l}\text { Solution } \\
\text { /wt\% }\end{array}$ & $\begin{array}{l}\text { Solvent } \\
\text { composition }\end{array}$ & $\begin{array}{l}\text { Density } \\
/ \mathrm{kg} \mathrm{m}^{-3}\end{array}$ & $\begin{array}{l}\text { Viscosity } \\
\text { /mPa s }\end{array}$ & $\begin{array}{l}\text { Surface } \\
\text { Tension } \\
/ \mathbf{m N ~ m}^{-1}\end{array}$ & $\begin{array}{l}\text { Electrical } \\
\text { conductivity } \\
/ \mu \mathrm{S} \mathrm{m}^{-1}\end{array}$ \\
\hline 10 & \multirow[t]{4}{*}{$100 \%$ Acetone } & 823 & 25.8 & 23.8 & 3.8 \\
\hline 12.5 & & 832 & 33.9 & 21.8 & 3.8 \\
\hline 15 & & 839 & 65.2 & 21.3 & 4.0 \\
\hline 17.5 & & 848 & 154 & 22.1 & 3.9 \\
\hline 10 & $80 \%$ Acetone & 896 & 65.8 & 28.6 & 8.6 \\
\hline 10 & $85 \%$ Acetone & 874 & 42.7 & 26.6 & 8.4 \\
\hline 10 & $90 \%$ Acetone & 856 & 36.0 & 25.2 & 8.7 \\
\hline 10 & $95 \%$ Acetone & 838 & 27.4 & 25.0 & 6.7 \\
\hline
\end{tabular}

135 Table 4: Characteristics of cellulose acetate solutions used.

136

\begin{tabular}{|c|c|c|c|c|c|}
\hline $\begin{array}{l}\mathbf{M}_{\mathrm{w}} \\
/ \mathrm{g} \mathrm{mol}^{-1}\end{array}$ & $\begin{array}{l}\text { Solution } \\
/ \mathrm{wt} \%\end{array}$ & $\begin{array}{l}\text { Density } \\
/ \mathrm{kg} \mathrm{m}^{-3}\end{array}$ & $\begin{array}{l}\text { Viscosity } \\
\text { /mPa s }\end{array}$ & $\begin{array}{l}\text { Surface } \\
\text { Tension } \\
/ \mathrm{mN} \mathrm{m}^{-1}\end{array}$ & $\begin{array}{l}\text { Electrical } \\
\text { conductiviby } \\
/ \mu \mathbf{S ~ m}^{-1} \quad 138\end{array}$ \\
\hline \multirow[t]{3}{*}{250,000} & $25: 75$ & 1088 & 855.1 & 58.1 & 827.2 \\
\hline & $14: 86$ & 1066 & 743.9 & 51.4 & 498.5 \\
\hline & $10: 90$ & 1056 & 603.9 & 49.2 & 390.4 \\
\hline 700,000 & $14: 86$ & 1034 & 535.9 & 51.1 & 371.2 \\
\hline
\end{tabular}

144 Table 5: Characteristics of carboxymethyl cellulose solutions used.

\subsection{Experimental setup for particle/fibre production}

147 Figure 1 illustrates the EHD experimental setup used. The solution was loaded into $10 \mathrm{~mL}$

148 syringes (Becton and Dickinson Company, Oxford, UK) attached with $0.76 \mathrm{~mm}$ inner diameter

149 capillary tubing (Sterilin, UK) to the stainless steel needle (15 G, ID: $2.06 \mathrm{~mm}$, OD: $2.67 \mathrm{~mm}$,

150 Stainless Tube \& Needle Co Ltd, Staffordshire, UK). The flow rate was controlled by a syringe 

precision voltage generator (FC $120 \mathrm{~W}$, Glassman Europe Limited, Bramley, UK) with capability of $0-30 \mathrm{kV}$ output. The ground electrode was attached to the metal collector. The solutions were subjected to a range of voltages $(0-20 \mathrm{kV})$, the flow rates used were 50 and 100 $\mu 1 \mathrm{~min}^{-1}$, and distance from collector to tip was 100 and $150 \mathrm{~mm}$. Samples were collected on glass microscope slides. All experiments were carried out at ambient conditions $\left(21^{\circ} \mathrm{C}\right.$ and 40 $50 \%$ humidity). A metallic plate, known as a guard plate, was attached to the steel needle and experiments conducted to evaluate its effect on microstructure morphology.

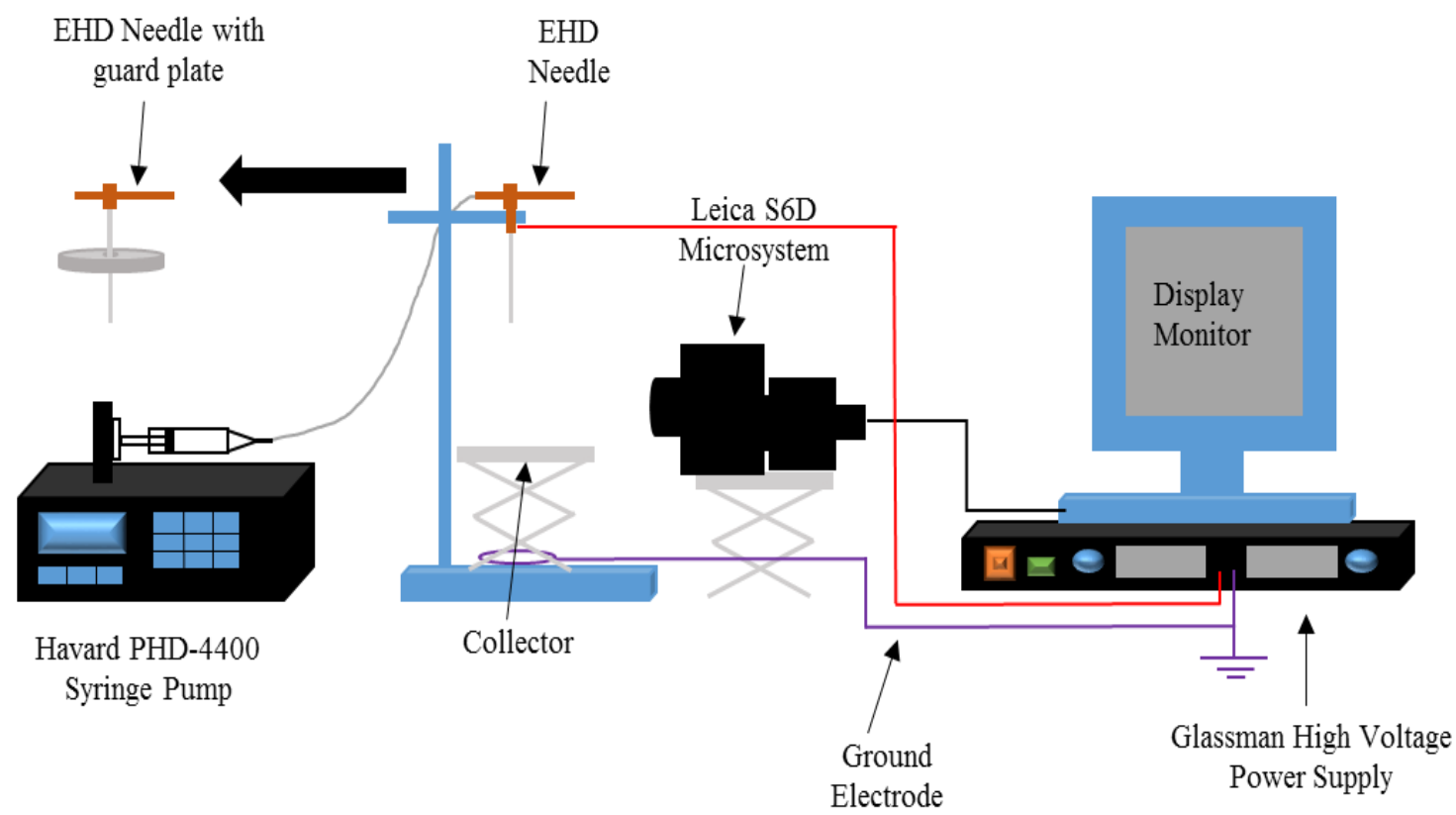

159 Figure 1: Schematic of the EHD set up.

\subsection{Sample Characterisation}

161 To observe the product shape, size, and morphology, samples were collected on glass microscope slides and images were obtained using an optical microscope (Zeiss Axiotech) fitted with a Q-imaging Micropublisher 3-3RTV camera. Scanning electron microscopy (Hitachi S-3400n), was performed on samples which were vacuumed coated with gold for 90 s. All images were analysed using ImageJ (public domain open source image processing software available online). The error bars shown in Figures 4-7, 9 and 11 indicate the standard deviation of the measurements, where $n=100$. 


\section{Results and Discussion}

169

170

171

\subsection{Ethyl Cellulose}

\subsubsection{Effect of concentration on microstructures}

Initially, solutions of 5, 10, 15, 20, 25 and 30wt\% were made and processed via EHD. Solutions of 5,10 and $15 \mathrm{wt} \%$ produced particles with the average diameter of $2.3,3.0$ and $3.2 \mu \mathrm{m}$, respectively. At these concentrations electrospraying occurred due to the lack of chain entanglements; physical interlocking of the polymer chains in solution (Husain, Lau et al. 2016). Solutions with low viscosities were more prone to the effect of the Rayleigh-Plateau instability brought on by surface tension (i.e. waves of instability along the jet cause it to break up into droplets resulting in particles) (Luo and Edirisinghe 2014).

As the droplet traversed towards the collector, the solvent evaporated, causing an increase of the charge density of the droplet until it reached a maximum value, known as the Rayleigh limit. At this point Coulomb fission occurred; this is a phenomenon where a droplet at its Rayleigh limit will eject some of its content in the form of "secondary" or "daughter" droplets, thereby reducing the charge of the "parent" droplet and its size (Almeria, Deng et al. 2010), this can bring about polydispersity in the sizes of the particle produced. Coulomb fission became increasingly apparent from figure $2 \mathrm{~A}$ to $2 \mathrm{C}$. Lower viscosity solutions are more susceptible to the effect of surface tension which promotes electrospraying rather than electrospinning, producing particles (Deitzel, Kleinmeyer et al. 2001). 

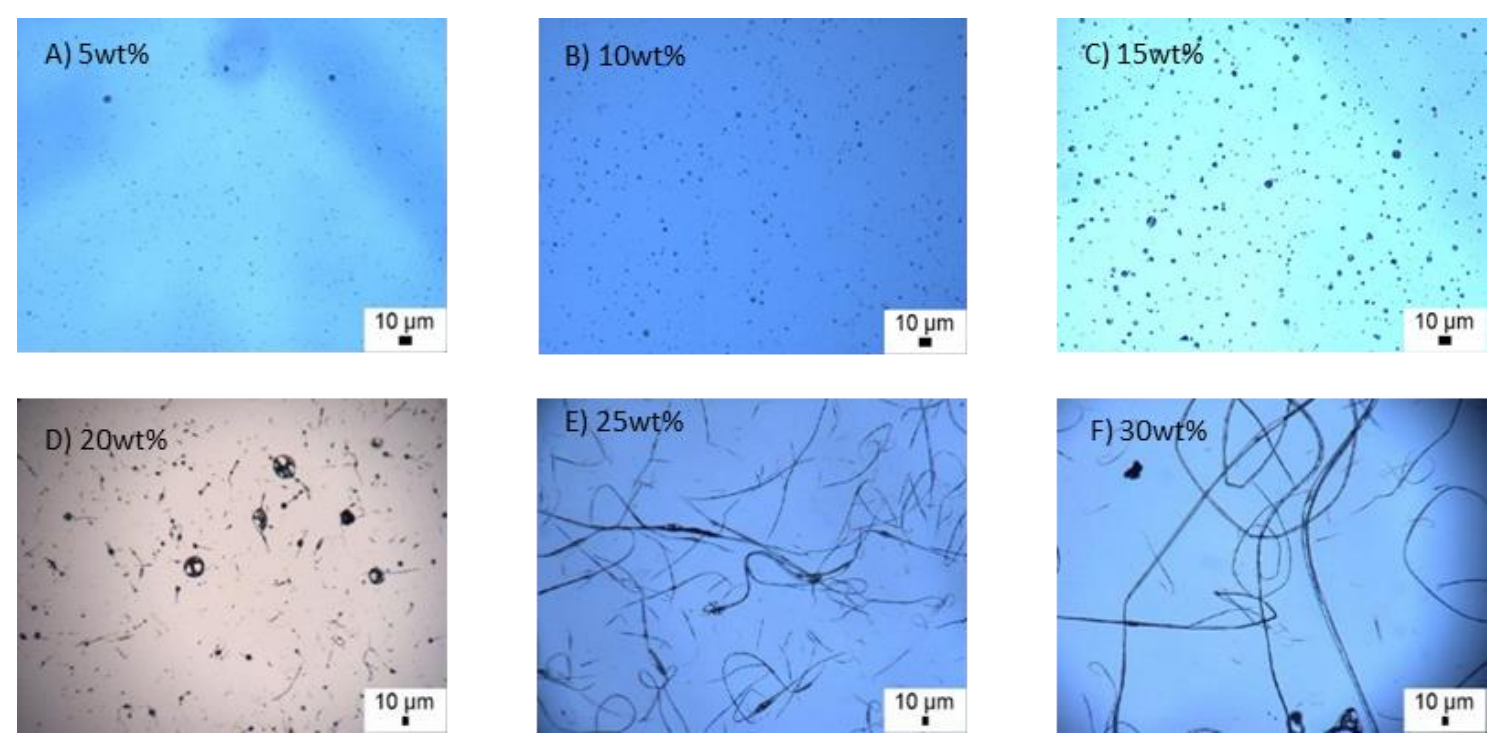

Figure 2: Optical micrographs of EC microstructures produced by EHD processing (applied voltage,

flow rate and collection distance were $15 \mathrm{kV}, 100 \mu \mathrm{L} \mathrm{min}^{-1}$ and $100 \mathrm{~mm}$, respectively)

The concentration of chain entanglements is controlled by polymer molecular chain length and solution polymer concentration. Increasing these simultaneously or individually will lead to an increase in chain entanglements pushing electrospraying to electrospinning (Shenoy, Bates et al. 2005, Almeria, Deng et al. 2010). When the entanglements between the polymer chains in the solution reach a critical level the jet is no longer able to break up; this brings about fibre formation (Li and Wang 2013). The increase in viscosities listed in Table 4, from 613 to 1652.5 $\mathrm{mPas}$, verify this increase of polymer chains present, and the transition is shown in Figures $2 \mathrm{C}$ to $2 \mathrm{E}$.

At $20 \mathrm{wt} \%$, particles with tails began to emerge. The increase in concentration enabled electrospinning creating the tails, however, the Rayleigh-Plateau instability had not been completely overcome.

At $25 \mathrm{wt} \%$ of EC, fibres were produced as a result of electrospinning. The fibres produced had an average diameter of $3.8 \mu \mathrm{m}$. The lack of spherical beads present on the fibre indicates the surface tension had been overcome despite the high value, $27.69 \mathrm{mN} \mathrm{m}^{-1}$. For highly viscose liquids (1652.5 mPas) the jet does not break up, instead, it travels as a whipping jet towards the 
grounded target (Taylor 1964). Surface tension plays a less significant role at higher viscosities, also enabling fibre formation (Deitzel, Kleinmeyer et al. 2001). The 30wt\% solution produced thick, ribbon-like fibres with an average width of $4 \mu \mathrm{m}$. Electrospinning with this solution was difficult due to the high polymer content. High polymer content meant rapid solvent evaporation, which caused blockages in the needle.

From these experiments, it was clear that there was an interesting region of transition between 15 to $25 \mathrm{wt} \%$, which required further investigation. To chart the transition, smaller increments of concentration were tested, solutions of $17,18,19,20,21,22,23$ and $24 \mathrm{wt} \%$ were also subjected to EHD and the gradual transition from particles to fibres was observed. Figure 3 displays the different morphologies produced as a result of changes in concentration (17$25 \mathrm{wt} \%$ ). At $17 \mathrm{wt} \%$, the chain entanglements were not sufficient enough to prevent the jet break-up and particles were still present. However, the viscosity of $17 \mathrm{wt} \%$ was $74 \mathrm{mPa}$ s higher than $15 \mathrm{wt} \%$, resulting in these particles having short tails.

Conversely, at $25 \mathrm{wt} \%$, the Rayleigh-Plateau instability had the least effect, which was evident by the lack of particles. When the electric field is applied, the electric force causes repulsion between polymer chains and forces the droplet to expand, which opposes the surface tension of the droplet trying to maintain the spherical shape and reduce the systems energy. As the charge builds, the repulsion overcomes the surface tension and with sufficient polymer entanglements, the well-known Taylor cone is formed and a jet is emitted (Garg and Bowlin 2011). However, the formation of beaded fibres shows the Rayleigh-Plateau instability is still present and had not been entirely overcome (Luo and Edirisinghe 2014). 

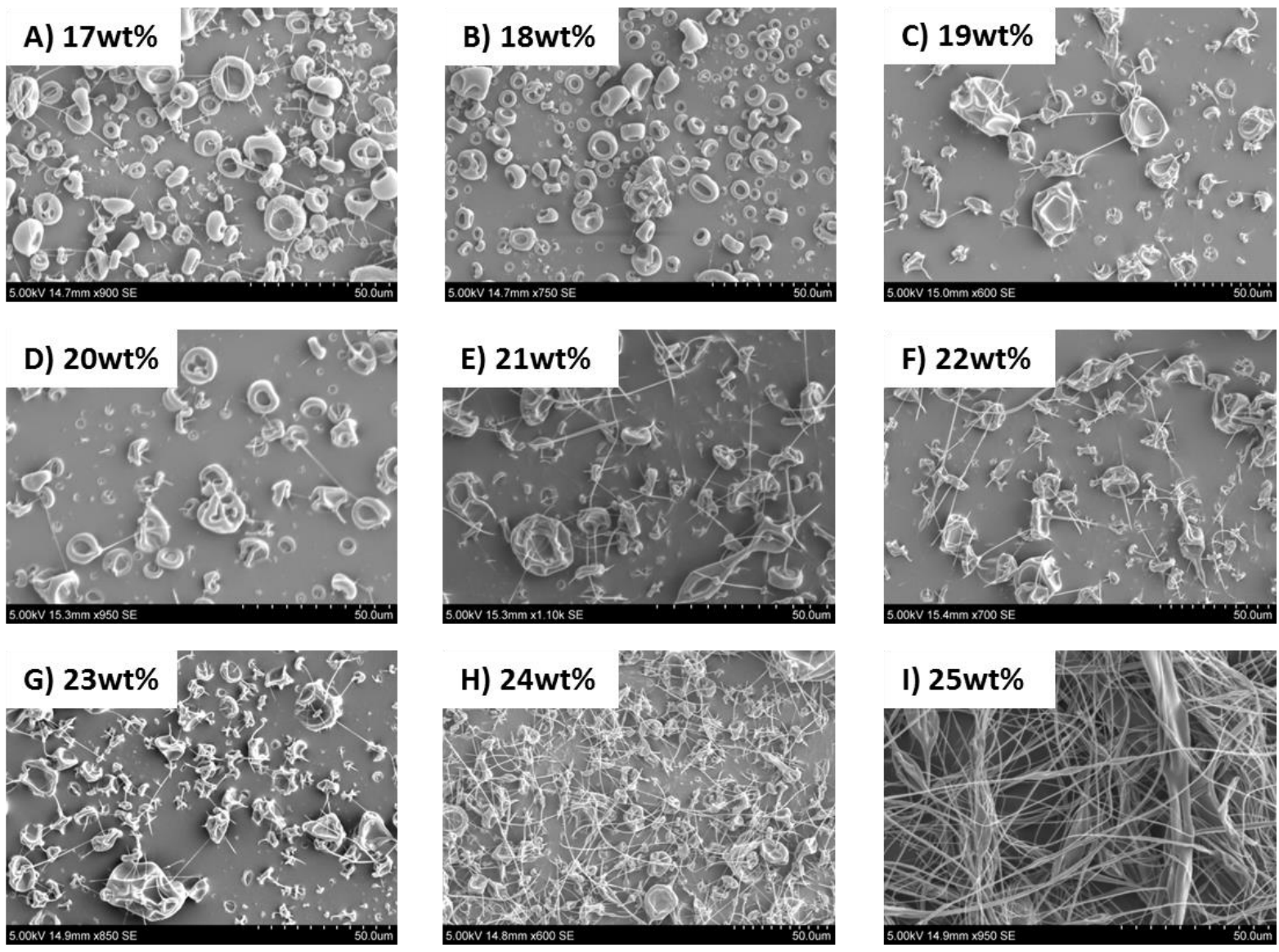

Figure 3: Scanning electron micrographs of EC microstructures produced by EHD processing (applied

voltage, flow rate and collection distance were $19 \mathrm{kV}, 100 \mu \mathrm{L} \mathrm{min}^{-1}$ and $150 \mathrm{~mm}$, respectively).

As the concentration increased, the resistance to Rayleigh-Plateau instabilities increased and the jet was less susceptible to break up (made longer fibres) and disturbances (caused less beading), as shown in Figure 3. Processing solutions above $25 \mathrm{wt} \%$ was difficult, and continuous electrospinning was not possible due to repeated blockages. The $25 \mathrm{wt} \%$ solution was deemed as the most desirable concentration of EC for uninterrupted fibre formation. 


\subsubsection{Effect of applied voltage on microstructure}

246 The effect of voltage on fibre diameter is disputed in the literature, with no consensus whether

247 there is a positive or negative correlation between the fibre diameter and voltage. Yuan et al.

248 (Yuan, Zhang et al. 2004) showed a reduction in fibre diameter with an increase in voltage in

249 their polysulfone/dimethylacetamide/acetone system. When the voltage is applied, it causes an increase in the net charge of the jet, improving the whipping instability and stretching resulting in production of thinner fibres (Hohman, Shin et al. 2001). On the contrary Zhang et al. (Zhang, Yuan et al. 2005), while working with a polyethylene oxide/water system showed an increase in fibre diameter with increasing voltage. The increase in voltage caused higher jet speed, reducing the flight time of the jet and the time allowed for the solvent to evaporate leading to thicker fibres (Hayati, Bailey et al. 1986). In the case of EC, as the voltage was increased, fibres with smaller diameters were obtained (Figure 4).

257

For this concentration, $25 \mathrm{wt} \%$, it appeared that the intermediate voltages, i.e. $16-18 \mathrm{kV}$, were the most stable, affected minimally by instabilities as shown by the lack of beading in fibres (Figures 4D-F). This high concentration had an increased number of polymer chains per unit volume of the solution, which means the effect of repulsion was greater. At $19 \mathrm{kV}$ (Figure 4G), for the given flow rate $\left(50 \mu \mathrm{L} \min ^{-1}\right)$, a stable cone jet was not formed. Rayleigh-Plateau instabilities became a dominant factor and this was evident by presence of circular beads. Changing the voltage, independent of the flow rate, increased the possibility of forming beaded fibres; for each flow rate there was a "critical voltage" where a stable Taylor cone formed, producing smooth fibres (Garg and Bowlin 2011). At $20 \mathrm{kV}$, the fusion of beads occurs, which brings down the fibre diameter. Higher electrical field strength, increases the repulsive forces acting on the polymer chain, thereby increasing the stretching that leads to a reduction in fibre diameter (Zhang, Yuan et al. 2005). 

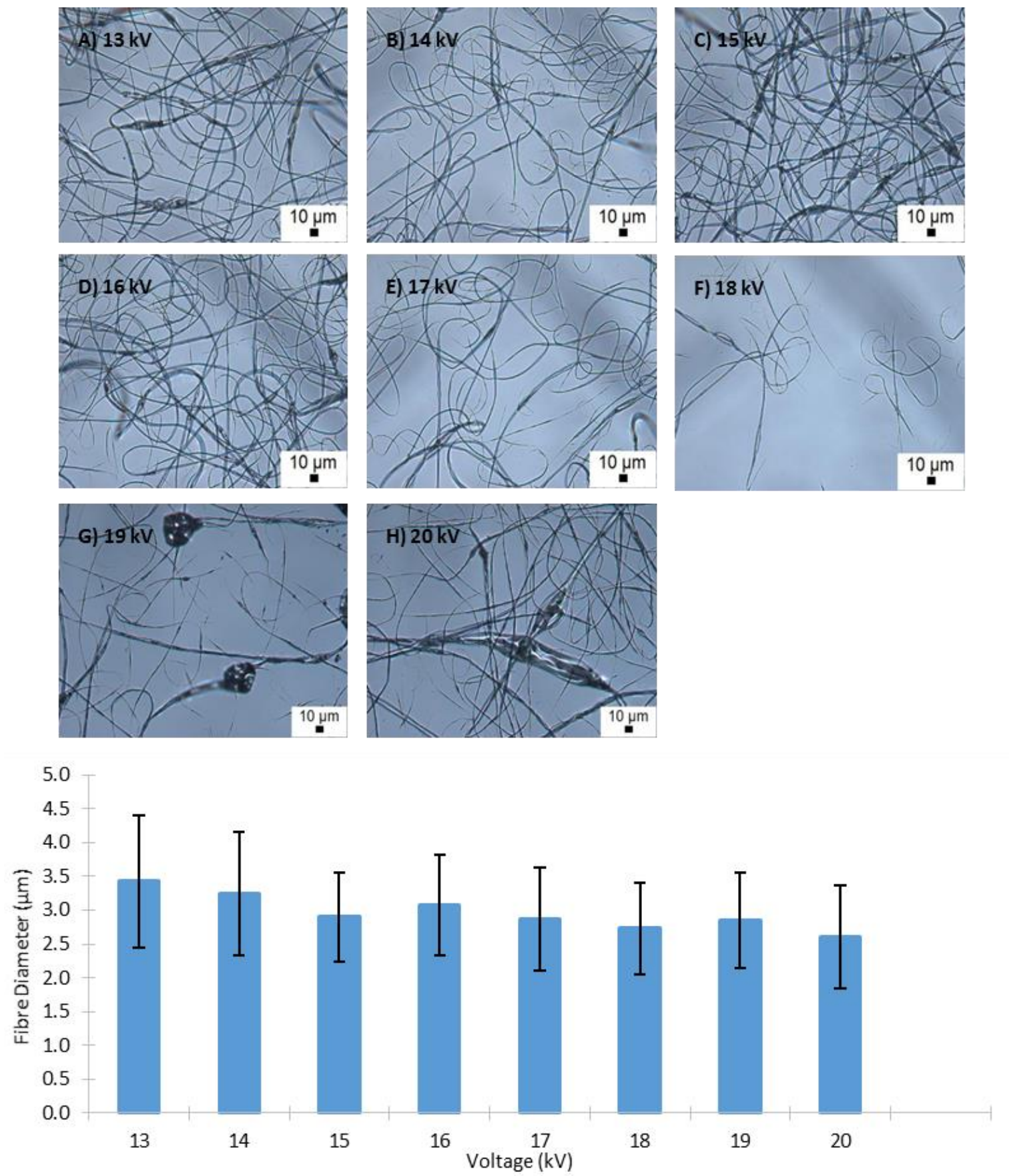

269 Figure 4: Optical micrographs of EC microstructures produced by EHD processing (concentration,

270 flow rate and collection distance were $25 \mathrm{wt} \%, 50 \mu \mathrm{L} \mathrm{min}^{-1}$ and $100 \mathrm{~mm}$, respectively), and variation in 271 fibre diameter with voltage. 


\subsubsection{Effect of flow rate on microstructure}

276 Changing the flow rate had a marked effect on morphology, as shown in Figure 5. Increased

277 flow rate increased the fibre diameter and droplet/bead diameter. When a larger volume of

278 solution streams from the needle tip per unit time i.e. $100 \mu \mathrm{L} \mathrm{min}{ }^{-1}$, the reduced solvent

279 evaporation formed larger fibres and beads compared to microstructures produced at $50 \mu \mathrm{L}$ $\min ^{-1}$. The increased flow rate allows for fewer stretching forces (Li and Wang 2013), as under

281 the same voltage, the same amount of energy competes to repel a greater number of polymer

282 chains flowing through the needle tip. This same amount of energy cannot reproduce the same

283 repelling forces for a greater flow rate (i.e. greater volume), hence larger fibres were produced.

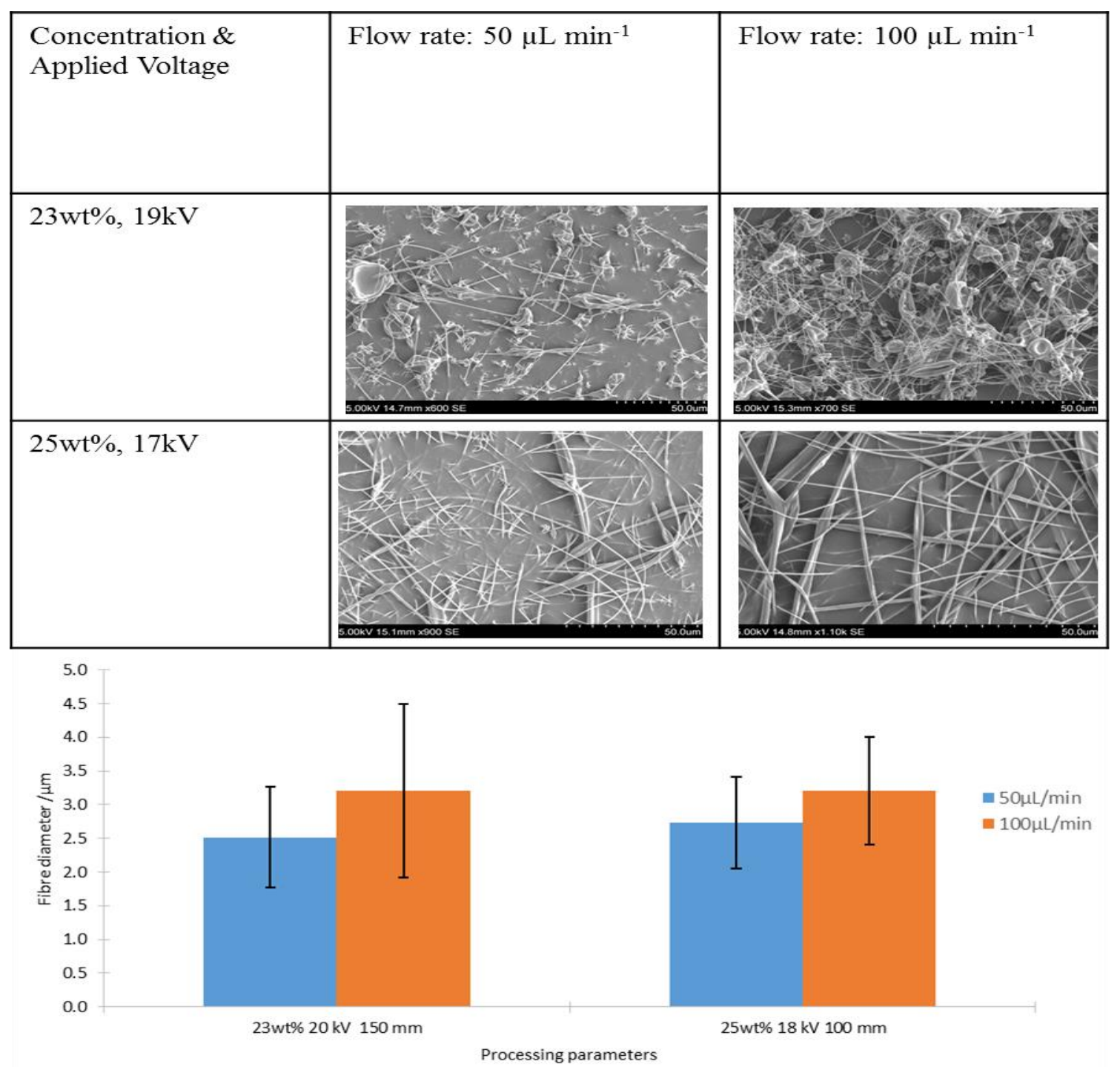


Figure 5: Scanning electron micrograph of EC microstructures produced by EHD processing with graph showing fibre diameter variation with flow rate (collection distance was $100 \mathrm{~mm}$ ). Samples were collected over $30 \mathrm{~s}$

The concentrations shown in Figure 5; 23 and $25 \mathrm{wt} \%$ and were processed with identical parameters. At a lower flow rate the difference in fibre diameter between 23 and $25 \mathrm{wt} \%$ is palpable, however, at $100 \mu \mathrm{L} \mathrm{min}^{-1}$ the diameters converge, which indicated the flow rate was limiting the extent the fibre diameter can be increased.

\subsubsection{Effect of collection distance on microstructure}

The dominant effect brought about by changing the distance between the tip and the collector, is the time allowed for solvent evaporation. Increasing this distance, increased the flight time and in turn, the time allowed for solvent evaporation to occur which decreased the fibre/bead diameter. As the jet traversed towards the collector, both internal charges and the external electric field induced a whipping motion which works to stretch the polymer chains, reducing the fibre diameter (Deitzel, Kleinmeyer et al. 2001). It is also at this point where solvent evaporation occurs, reducing the fibre diameter. Table 7 demonstrates the change in fibre diameter, fibres collected at $150 \mathrm{~mm}$ have a smaller diameter compared to $100 \mathrm{~mm}$. The solution with $24 \mathrm{wt} \% \mathrm{EC}$ was able to form thinner fibres, albeit with slight beading, as it has a higher electrical conductivity compared to $25 \mathrm{wt} \%$ (Table 5) as increased conductivity leads to thinner fibres.

\begin{tabular}{|l|l|l|}
\hline Concentration & Tip to collector distance:100mm & Tip to collector distance:150mm \\
\hline $24 \mathrm{wt} \%$ & $2.52 \pm 0.64$ & $1.37 \pm 0.34$ \\
\hline $25 \mathrm{wt} \%$ & $3.5 \pm 0.98$ & $2.5 \pm 0.52$ \\
\hline
\end{tabular}

Table 6: Fibre diameter as a function of tip to collector distance, for 24 and $25 \mathrm{wt} \%$ ethyl cellulose solutions 


\subsubsection{Effect of concentration on microstructure}

310 Solutions of $10-17.5 \mathrm{wt} \%$ of cellulose acetate were electrospun. The effect of concentration is

311 similar to that discussed for EC. Figure 6B shows a positive correlation between the polymer

312 concentration and fibre diameter. As with EC, the increase in CA concentration increased the 313 entanglement between the molecular chains.

314 Figure 6A displays the change in morphology as the concentration increases. At 10wt $\%$, the

315 fibres are heavily beaded and have the smallest fibre diameter at $2.32 \mu \mathrm{m}$. Although the 316 concentration is high enough to bring about electrospinning, demonstrated by the presence of 317 fibres, the viscosity was not high enough to resist the instabilities, along with the highly volatile 318 nature of acetone, beads were formed ( $\mathrm{Li}$ and Wang 2013). Increasing the concentration to $31912.5 \mathrm{wt} \%$, produced fibres with much less beading.

320 At concentration $15 \mathrm{wt} \%$, the fibre diameter increased to $3.62 \mu \mathrm{m}$. Increasing the concentration 321 makes the solution less prone to the drawing process which stretches the jet as it whips towards 322 the collector, resulting in larger diameters. Concentration $17.5 \mathrm{wt} \%$ produced the fibres with a 323 diameter of $5.5 \mu \mathrm{m}$, showing this concentration was the most resistant to the stretching due to 324 the high level of chain entanglements preventing this. 

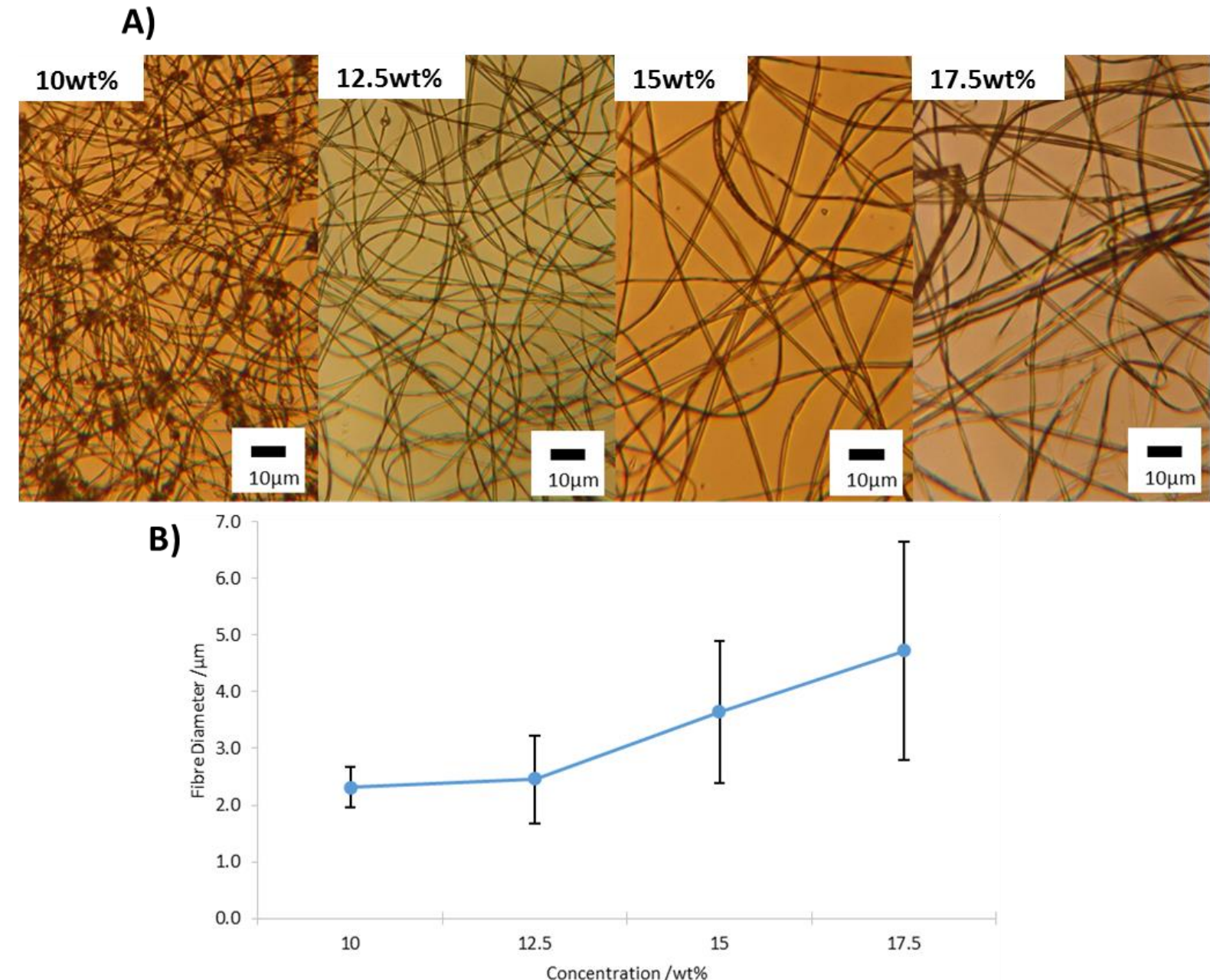

325 Figure 6: A) Optical micrographs of CA microstructures produced by EHD processing with the following solution concentrations L-R 10, 12.5, 15 and $17.5 \mathrm{wt} \%$ in acetone only

327 B) Variation in fibre diameter with polymer concentration (applied voltage, flow rate and collector distance were $12 \mathrm{kV}, 6 \mathrm{~mL} \mathrm{~h}^{-1}$ and $100 \mathrm{~mm}$, respectively).

\subsubsection{Effect of solvent on microstructure}

331 In an attempt to reduce the beading in the $10 \mathrm{wt} \%$ sample (Figure 6A), water was added in increments of $5 \%$ (vol.) and the morphological changes were observed. Water is a non-solvent for CA, but can be added to acetone on order to reduce the evaporation rate and change the 334 fibre diameter (Frey 2008). Adding water to the solution had a noticeable effect on the fibre morphology as shown in Figure 7. It simultaneously reduced the beading and increased the 
341 viscosity of the liquid, therefore instabilities were able to influence the jet and give rise to

342 beading (Luo, Stride et al. 2012).

343
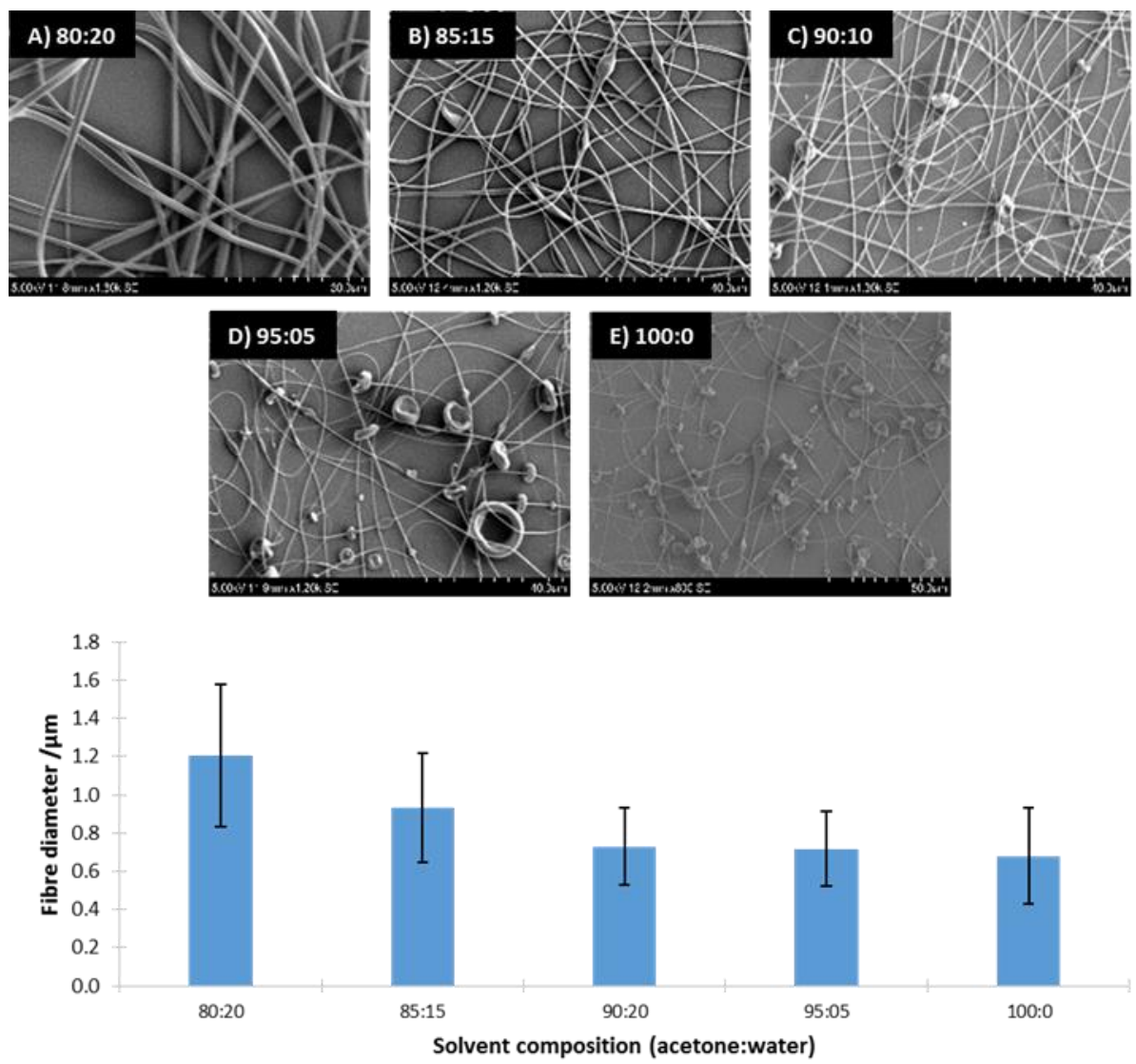

Figure 7: Scanning electron micrographs of CA microstructures produced by EHD processing and variation in fibre diameter with solvent composition (concentration, applied voltage, flow rate and collector distance were $10 \mathrm{wt} \%, 13 \mathrm{kV}, 4 \mathrm{~mL} \mathrm{~h}^{-1}$ and $100 \mathrm{~mm}$, respectively). 


\subsubsection{Effect of guard plate on microstructure}

352 The guard plate can be added to an EHD set up to strengthen the electric field and to control

353 the deposition area of the fibres. In this investigation, the effect on the fibre diameter was

354 examined. The solutions which produced the largest diameter, $17.5 \mathrm{wt} \%$, and solution which

355 gave the most beaded sample, $10 \mathrm{wt} \%$, both with 80:20 acetone/water solvent system, were

356 tested using the guard plate. The guard plate reduced fibre dispersity of samples collected from

357 17.5wt\%; from 0.54 (Figure 8A (i)) to 0.49 (Figure 8A (ii)). Fibres collected from 10wt\%

358 (Figures 8B (i-ii)) showed a reduction in beading on the fibres upon adding the guard plate.

359
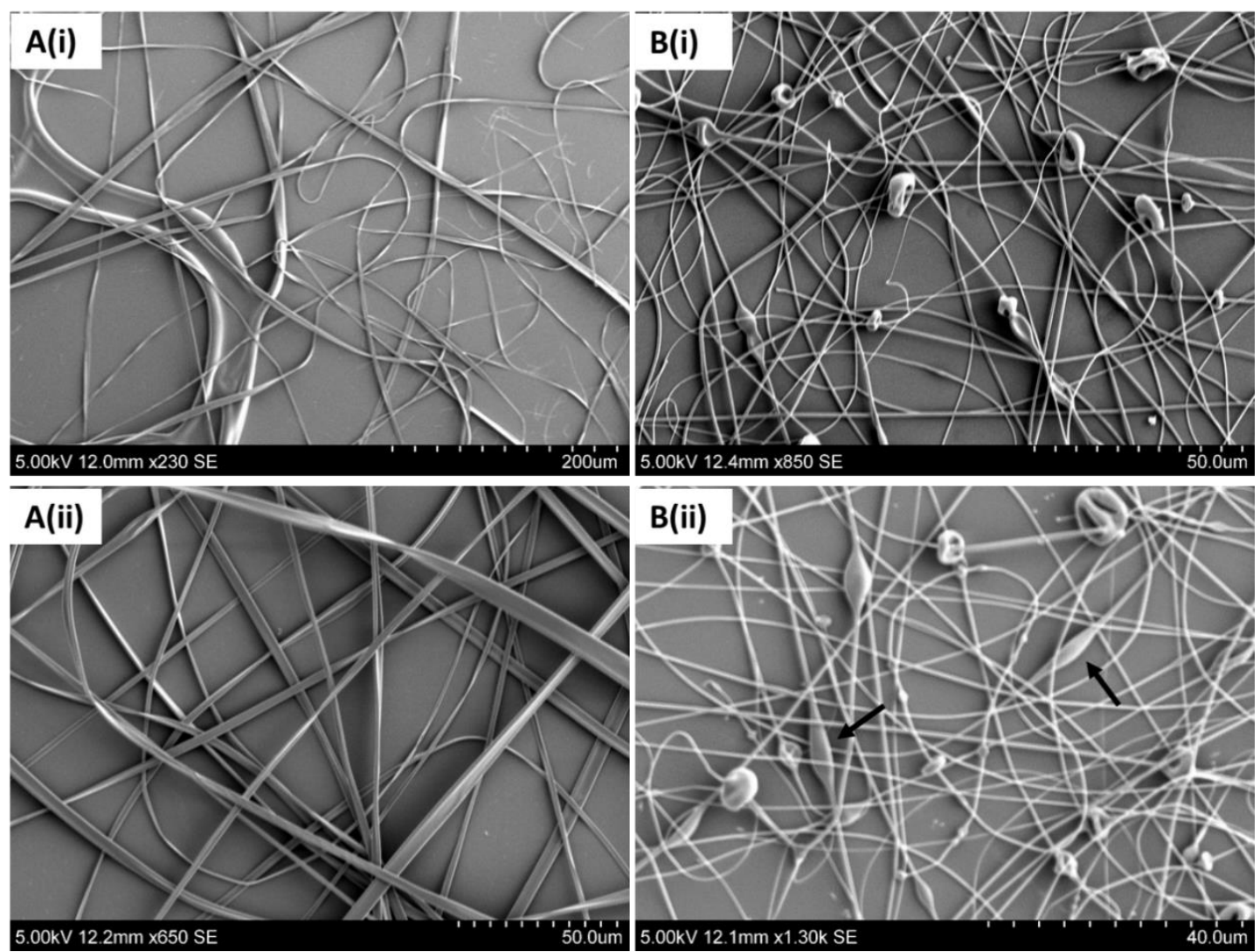

Figure 8: Scanning electron micrographs of CA microstructures produced by EHD processing

361 (concentration, voltage, flow rate, collection distance and solvent system were (A) $17.5 \mathrm{wt} \%, 13 \mathrm{kV}, 4$

$362 \mathrm{ml} \mathrm{h}^{-1}$ and $100 \mathrm{~mm}$, in acetone only (i) no guard plate and (ii) with guard plate, (B) $10 \mathrm{wt} \%, 13 \mathrm{kV}, 4 \mathrm{ml}$

$\mathrm{h}^{-1}$ and $100 \mathrm{~mm}$, in 80:20, (i) no guard plate and (ii) with guard plate, respectively). 
The guard plate strengthens the electric field, which affected the whipping instability; a larger force was exerted on the jet increasing the speed, and in turn increasing the stretching resulting in reducing the fibre diameter (Yang, Jia et al. 2008) and supressing the formation of rounded beads. Figures $8 \mathrm{~B}$ (i) to (ii) shows the suppression of some beads to elongated/spindle like beads along the fibre, as indicated by arrows.

\subsection{Carboxymethyl Cellulose}

Poly(ethylene oxide) was added to the carboxymethyl cellulose (CMC) solution to act as a spinning agent, as on its own, CMC cannot be electrospun (Brako, Raimi-Abraham et al. 2015). This blend was made up of $4 \mathrm{wt} \%$ carboxymethyl cellulose in water and $15 \mathrm{wt} \%$ poly(ethylene oxide) in water. These two solutions were mixed at the following ratios 90:10, 86:14 and 75:25 as used by Brako et al. (Brako, Raimi-Abraham et al. 2015) with two different molecular weights of carboxymethyl cellulose; 250,000 and 700,000 $\mathrm{g} \mathrm{mol}^{-1}$.

\subsubsection{Effect of molecular weight on microstructure}

Fibres produced from CMC70/PEO blend had a larger diameter compared to CMC25/PEO. The longer polymer chain found in CMC70 participated in more physical entanglements to such a degree that the drawing forces were resisted, leading to a larger average fibre size of $1.12 \mu \mathrm{m}$ compared to $0.89 \mu \mathrm{m}$ for $\mathrm{CMC} 25 / \mathrm{PEO}$ fibres.

Changing the molecular weight caused a change in morphology as shown in Figure 9. The fibres produced from $250,000 \mathrm{~g} \mathrm{~mol}^{-1}$ had more bends than the products of 700,000 $\mathrm{g} \mathrm{mol}^{-1}$. As mentioned previously, lower molecular weight is more susceptible to the instabilities brought on by the electrical field, resulting in a twisted appearance. The bending or "buckling" are formed by molecular repulsion in the jet (Han, Reneker et al. 2007). 


\begin{tabular}{|l|l|}
\hline Molecular weight $/ \mathbf{g ~ m o l}^{-\mathbf{1}}$ & Fibre diameter $/ \boldsymbol{\mu m}$ \\
\hline 250,000 & $0.89 \pm 0.35$ \\
\hline 700,000 & $1.12 \pm 0.23$ \\
\hline
\end{tabular}

Table 7: Fibre diameter as a function of molecular weight; 86:14 CMC/PEO w/w.
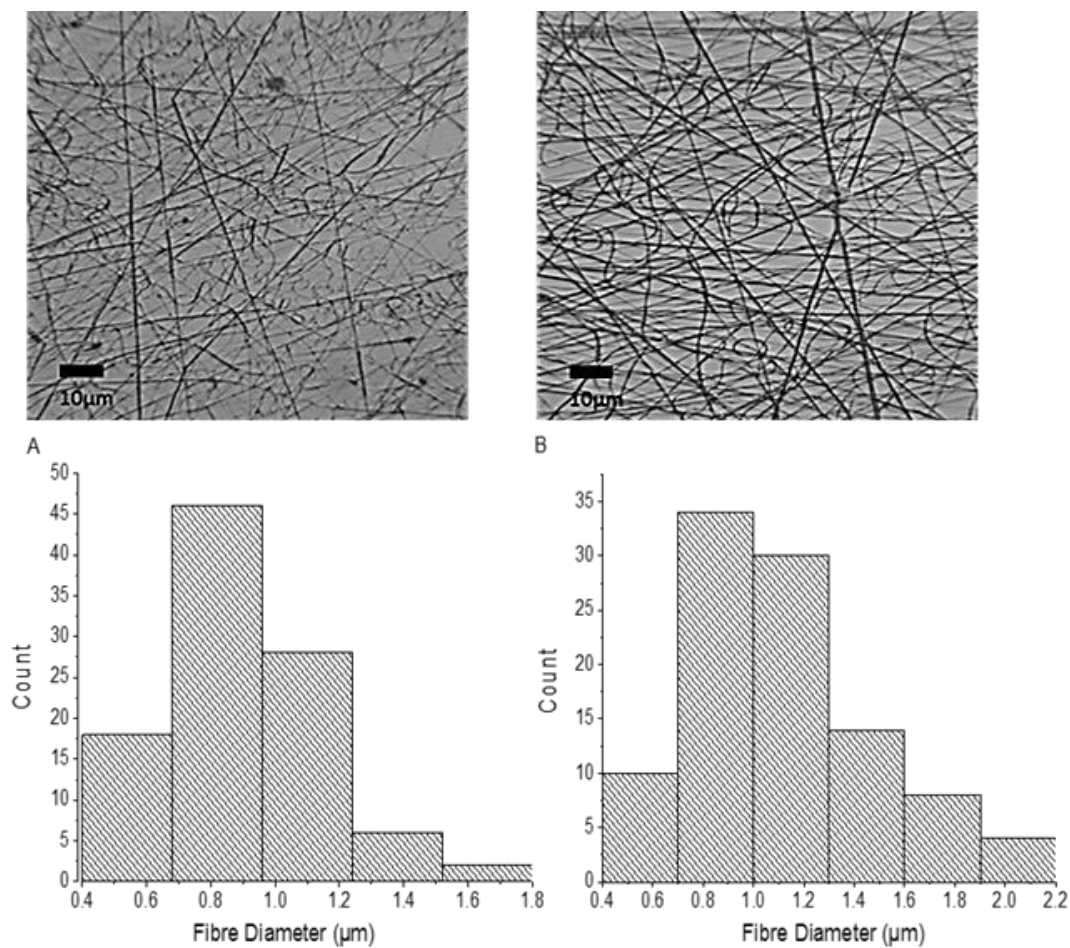

396

Figure 9: Optical micrographs of CMC/PEO fibres L-R 250,000 $\mathrm{g} \mathrm{mol}^{-1}$ and 700,000 $\mathrm{g} \mathrm{mol}^{-1}$ (voltage, flow rate and collection distance were $15 \mathrm{kV}, 5 \mu \mathrm{L} \mathrm{min}^{-1}$ and $100 \mathrm{~mm}$, respectively).

\subsubsection{Effect of CMC/PEO content on microstructure}

400

An increase in $\mathrm{CMC}$ content in the blend drove down the fibre diameter as shown by Figure 10. CMC has a greater chain length compared to PEO, 250,000 and 200,000 $\mathrm{g} \mathrm{mol}^{-1}$, respectively. Enlarging the $\mathrm{CMC} 25$ content rather than $\mathrm{PEO}$ meant more polymer chain entanglements were occurring, but not to the extent of CMC70 as previously mentioned. This level of chain entanglement did not hinder the drawing process, instead making the fibres more prone to the stretching phase of the electrospinning process and resulting in smaller fibre diameter (Shenoy, Bates et al. 2005). 

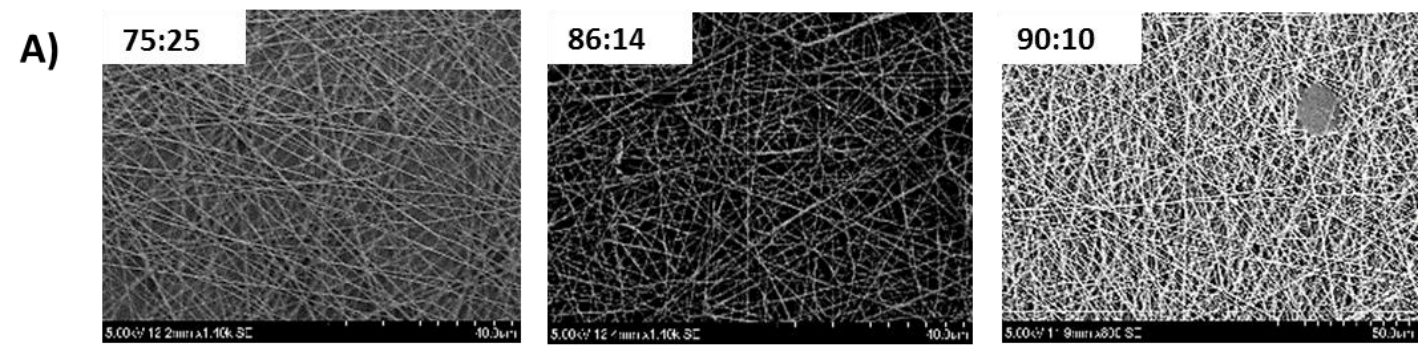

B)

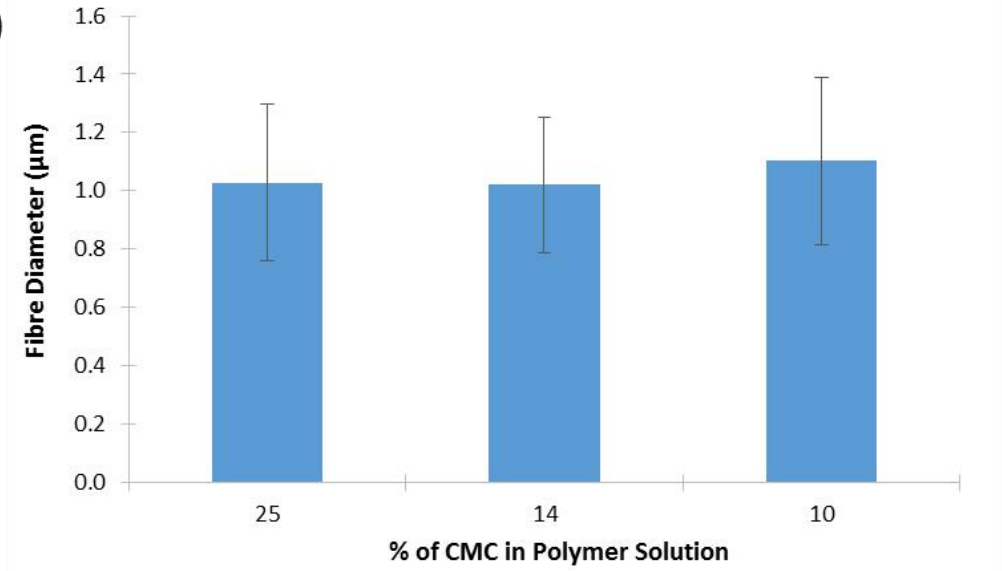

407 Figure 10: A) Scanning electron micrographs of CMC 25/PEO fibres at the following blends

408

409

410

411

412

413

414

415

416

417

418

419

420

421

422

423

424

425
PEO:CMC a) 90:10, b) 86:14 and c) 75:25. B) Graph showing effect of CMC proportion in solution

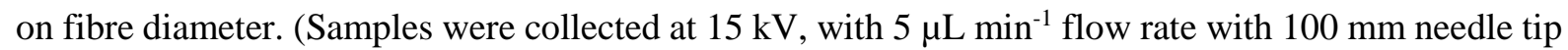
to collector distance.) 


\section{Conclusions}

427 Cellulose derivatives, are commonly processed with unfavourable solvents. If cellulose derivatives are to play a bigger role in medical materials, this has to be addressed. In this work, a range of microstructures were produced with three cellulose derivatives, all solubilised in non-toxic solvents, whilst using electrohydrodynamic processing. After initial experiments with EC and CA further tests were carried out to delve deeper in the electrospinnability of these polymers in safe solvents. EC had a transitional period of interest, $17-25 \mathrm{wt} \%$, this was further investigated to identify how the structures transitioned from particle to fibre. Beyond $25 \mathrm{wt} \%$ was proven difficult to electrospin, however, this concentration gave continuous fibres, while using the non-toxic binary solvent system of ethanol and water. CA was electrospun with acetone, however, samples collected from $10 \mathrm{wt} \%$ was heavily beaded. The solvent system was adjusted and $20 \%$ (vol.) water was added to acetone in order to reduce the evaporation rate, producing smooth fibres. This finding showed instead of increasing polymer concentration to reduce beading, manipulating the solvent system alone brought about the same effect. Adding the guard plate also played a role in reducing beading effect and fibre size. CMC with $\mathrm{M}_{\mathrm{W}}$ 700,000 led to larger fibres compared to $\mathrm{M}_{\mathrm{w}} 250,000$. In the CMC/PEO blend, increasing the content of polymer with higher $\mathrm{M}_{\mathrm{w}}$ from 1.03 to $1.10 \mu \mathrm{m}$. This gives two routes/options to adjust the fibre iameter or even the morphology of the fibre (either by varying the CMC concentration, or by changing the molecular weight). Despite the challenge with electrohydrodynamic atomization using organic solvents, this work has shown the potential to produce a range of structures across three CD's with environmentally friendly solvents which could potentially replace the use of cellulose in biomedical materials. 
Agarwal, S., J. H. Wendorff and A. Greiner (2008). "Use of electrospinning technique for biomedical applications." Polymer 49(26): 5603-5621.

Almeria, B., W. Deng, T. M. Fahmy and A. Gomez (2010). "Controlling the morphology of electrospray-generated PLGA microparticles for drug delivery." J Colloid Interface Sci 343(1): 125133.

Brako, F., B. Raimi-Abraham, S. Mahalingam, D. Q. M. Craig and M. Edirisinghe (2015). "Making nanofibres of mucoadhesive polymer blends for vaginal therapies." European Polymer Journal 70: 186-196.

Castilla-Casadiego, D. A., M. Maldonado, P. Sundaram and J. Almodovar (2016). "“Green” electrospinning of a collagen/hydroxyapatite composite nanofibrous scaffold." $\underline{\text { MRS Communications }}$ 6(04): 402-407.

Cui, W., Y. Zhou and J. Chang (2016). "Electrospun nanofibrous materials for tissue engineering and drug delivery." Science and Technology of Advanced Materials 11(1): 014108.

Deitzel, J. M., J. Kleinmeyer, D. Harris and N. C. Beck Tan (2001). "The effect of processing variables on the morphology of electrospun nanofibers and textiles." Polymer $\mathbf{4 2}$.

Duarte, A. R., M. D. Gordillo, M. M. Cardoso, A. L. Simplicio and C. M. Duarte (2006). "Preparation of ethyl cellulose/methyl cellulose blends by supercritical antisolvent precipitation." Int J Pharm 311(1-2): 50-54.

Eltayeb, M., P. K. Bakhshi, E. Stride and M. Edirisinghe (2013). "Preparation of solid lipid nanoparticles containing active compound by electrohydrodynamic spraying." Food Research International 53(1): 88-95.

Formhal, A. (1934). Process and apparatus for preparing artificial threads, Google Patents. Frenot, A., M. W. Henriksson and P. Walkenström (2007). "Electrospinning of cellulose-based nanofibers." Journal of Applied Polymer Science 103(3): 1473-1482.

Frey, M. W. (2008). "Electrospinning Cellulose and Cellulose Derivatives." Polymer Reviews 48(2): 378-391.

Garg, K. and G. L. Bowlin (2011). "Electrospinning jets and nanofibrous structures." Biomicrofluidics 5(1): 13403.

Han, T., D. H. Reneker and A. L. Yarin (2007). "Buckling of jets in electrospinning." Polymer 48(20): 6064-6076.

Hayati, I., A. Bailey and T. F. Tadros (1986). "Investigations into the Mechanism of Electrohydrodynamic Spraying of Liquids " Journal of Colloid and Interface Science 117(1). Hohman, M. M., M. Shin, G. Rutledge and M. P. Brenner (2001). "Electrospinning and electrically forced jets. I. Stability theory." Physics of Fluids 13(8): 2201.

Husain, O., W. Lau, M. Edirisinghe and M. Parhizkar (2016). "Investigating the particle to fibre transition threshold during electrohydrodynamic atomization of a polymer solution." Material Science and Engineering C: Materials for Biological Applications 65: 240-250.

Jeun, J. P., Y. M. Lim, J. H. Choi, H. S. La, P. H. Kang and Y. C. Nho (2007). "Preparation of EthylCellulose Nanofibers via An Electrospinning." Solid State Phenomena 119: 255-258.

Kessick, R. and G. Tepper (2003). "Microscale electrospinning of polymer nanofiber interconnections." Applied Physics Letters 83(3): 557.

Lee, K. H., H. Y. Kim, H. J. Bang, Y. H. Jung and S. G. Lee (2003). "The change of bead morphology formed on electrospun polystyrene fibers." Polymer 44(14): 4029-4034.

Li, Z. and C. Wang (2013). "Effects of Working Parameters on Electrospinning." 15-28. Liu, H. and Y.-L. Hsieh (2002). "Ultrafine fibrous cellulose membranes from electrospinning of cellulose acetate." Journal of Polymer Science Part B: Polymer Physics 40(18): 2119-2129. Liu, X., T. Lin, Y. Gao, Z. Xu, C. Huang, G. Yao, L. Jiang, Y. Tang and X. Wang (2012). "Antimicrobial electrospun nanofibers of cellulose acetate and polyester urethane composite for wound dressing." J Biomed Mater Res B Appl Biomater 100(6): 1556-1565.

Loffler, H., G. Kampf, D. Schmermund and H. I. Maibach (2007). "How irritant is alcohol?" British Journal of Dermatology 157(1): 74-81.

Luo, C. and M. Edirisinghe (2014). "Core-Liquid-Induced Transition from Coaxial Electrospray to Electrospinning of Low-Viscosity Poly (lactide-co-glycolide) Sheath Solution." Macromolecules 47(22): 7930-7938. 
Luo, C., M. Nangrejo and M. Edirisinghe (2010). "A novel method of selecting solvents for polymer electrospinning." Polymer 51(7): 1654-1662.

508 Luo, C. J., E. Stride and M. Edirisinghe (2012). "Mapping the Influence of Solubility and Dielectric Constant on Electrospinning Polycaprolactone Solutions." Macromolecules 45(11): 4669-4680. Miyamoto, T., S.-i. Takahashi, H. Ito and H. Inagaki (1989). "Tissue biocompatibility of cellulose and its derivatives." Journal of Biomedical Materials Research 23: 125-133.

Park, J.-Y., J.-I. Kim and I.-H. Lee (2015). "Fabrication and Characterization of Antimicrobial Ethyl Cellulose Nanofibers Using Electrospinning Techniques." Journal of Nanoscience and Nanotechnology 15(8): 5672-5675.

Reneker, D. H., A. L. Yarin, H. Fong and S. Koombhongse (2000). "Bending instability of electrically charged liquid jets of polymer solutions in electrospinning." Journal of Applied Physics 87(9): 4531. Shenoy, S. L., W. D. Bates, H. L. Frisch and G. E. Wnek (2005). "Role of chain entanglements on fiber formation during electrospinning of polymer solutions: good solvent, non-specific polymerpolymer interaction limit." Polymer 46(10): 3372-3384.

Shokri, J. and K. Adibki (2013). "Application of Cellulose and Cellulose Derivatives in Pharmaceutical Industries."

Smallwood, I. M. (1996). Handbook of organic solvent properties. London, Hodder Headline Group. Son, W. K., J. H. Youk, T. S. Lee and W. H. Park (2003). "Electrospinning of Ultrafine Cellulose Acetate Fibers: Studies of a New Solvent System and Deacetylation of Ultrafine Cellulose Acetate Fibers." Journal of Polymer Scienc: Polymer Physics 42: 5-11.

Son, W. K., J. H. Youk and W. H. Park (2006). "Antimicrobial cellulose acetate nanofibers containing silver nanoparticles." Carbohydrate Polymers 65(4): 430-434.

Taylor, G. (1964). Disintegration of Water Drops in an Electric Field. Proceedings of the Royal Society of London, London, The Royal Society.

Tungprapa, S., T. Puangparn, M. Weerasombut, I. Jangchud, P. Fakum, S. Semongkhol, C. Meechaisue and P. Supaphol (2007). "Electrospun cellulose acetate fibers: effect of solvent system on morphology and fiber diameter." Cellulose 14(6): 563-575.

Yang, Y., Z. Jia, J. Liu, Q. Li, L. Hou, L. Wang and Z. Guan (2008). "Effect of electric field distribution uniformity on electrospinning." Journal of Applied Physics 103(10): 104307. Yuan, X., Y. Zhang, C. Dong and J. Sheng (2004). "Morphology of ultrafine polysulfone fibers prepared by electrospinning." Polymer International 53(11): 1704-1710.

Zhang, C., X. Yuan, L. Wu, Y. Han and J. Sheng (2005). "Study on morphology of electrospun poly(vinyl alcohol) mats." European Polymer Journal 41(3): 423-432. 